\title{
Teaching Function and Practice Thinking of Psychological Movies
}

\author{
Weidong $\mathrm{Wu}$ (Corresponding author) \\ Education Department of Dezhou University, Shandong Dezhou 253023, China \\ E-mail:wwd0911@sohu.com
}

\begin{abstract}
Psychology teaching was implemented in virtue of excellent psychological movies, which not only could help to stimulate students' interest, and make the abstract theory concretion and visualization, but also provide the scenes similar to the reality for students' learning with attempts to improve their learning achievement. However, as for the exhibition of psychological phenomenon, psychological movies had its own limitations, and the teaching process was relatively time-consuming. Therefore, it was only applied as one of the teaching assistant forms.
\end{abstract}

Keywords: Psychological movies, Psychology teaching, Function, Thinking

\section{Introduction}

As a comprehensive art, film was closely associated with psychology. In the film categories, there is a special type of film, namely psychological movie. It came into being in the 1930s-1940s, when Freud's psychoanalytic theory was very popular among the United States. Hollywood had produced a large number of psychological movies reflecting the psychopathy and psychology, and these films were called psychological movies (Lv, 2005, PP. 39-40). Afterwards, a large quantity of psychological movies thrived in the world moviedom, and those movies reflecting psychology became increasing widespread.

Psychology teaching was a special social activity through the teaching, and was also a special activity of systematically teaching students research achievements of psychology in virtue of certain organization forms. The contents between what psychological movies reflected and expressed and psychology teaching was consistent to some degree, and those movies were completely became the available materials for psychology teaching. Therefore, in psychology teaching, it was feasible to achieve the teaching tasks of psychology-related courses using psychological movies.

In recent years, I carefully selected 20 psychological movies such as "Concubine," "Horse Whisperer", "Edward Doctor," "Good Will Hunting" and so on, and applied them in the teaching of several courses such as "Personality Psychology", "Psychological Counseling", "Public Psychology" and so on. In combination with the specific content of each course I guided the students to appreciate those films, and practices showed that it was a more effective approach to complete the teaching tasks by dint of psychological movies.

\section{Role of psychological movies in psychology teaching}

\subsection{Attract students' attention and interest}

Picture and sound were the basic elements of film language, furthermore, film's plot and story line, dynamic modeling and comprehensive artistic approaches (Jin, 1999, PP. 48-6048-60) all made films an art which people were prone to accept. Classroom teaching mainly resorted to languages, and was far less compared to the movies, whether in multi-dimensional nature of information transmission, or expression means, etc. Full attention was the prerequisite psychological condition for students to be engaged in learning activities and effectively acquire knowledge, and film's own characteristics determined that they would attract and maintain students' attention spontaneously. If based on the unconscious attention imposed by films, teachers steered the purpose and directivity of students' attention, and carried out pertinent explanation and analysis, and then students' unconscious attention could be transformed into conscious attention which contained psychology contents.

In 1901, Thorndike, educational psychologist in USA, conducted the famous "graphic decision experiments" using college students as subjects. On this basis, he pointed out that learning transfer would occur as long as there were common elements between two topics (Mo, 2002, PP. 268-269). What psychological movies reflected was consistent with several psychology courses, and therefore, teachers played a leading role consciously when students were enjoying psychological movies. Hence, students would have a further deep view of what psychological movies reflected. Positively driven by the direct interest resulted from psychological movies, interests in psychological movies would soon be transformed into other interest in the contents of relevant disciplines. 
For example, during the process of appreciating the classic psychological film "Edward Doctor", induced by the suspense one by one set by the suspense master Alfred Hitchcock, students would get into the ups and downs of the plot deep, the interests in the film plots would be inspired promptly, and with growing awareness contradictions and plots developments inspired by suspense, students would naturally concern about the fate of the hero and the story ending. Who the hell was Edward doctor? Why did he imitate the president of the hospital? Why did he lose memory? Why did he think that he was the murder while he didn't kill the president? Why did he have such bizarre dreams? These issues would always remain in the minds of students during the process of appreciation, and they could not help to seek for explanations of those issues. With the film's interpretation of psychoanalytic doctrine, they would find answers from this theory, and interests in these issues would also be transformed into the interests in the theory eventually.

\subsection{Make abstract psychological theory concrete and visual}

Psychology is a cross-discipline closely associated with the disciplines such as philosophy, history, sociology and so on, and contents related to psychology courses were abstract and profound, which was tough for students to understand and grasp. As is well known to us all, students' learning is a mental process accepting main indirect experiences. What courses related to psychology contained is the wisdom crystallization of psychologists over the past century, and a kind of indirect experiences for students. However, accepting those indirect experiences by students should resort to specific and visual sensual experience. The plot is specific, the characters are vivid, and the expressions of the issues are also lively in psychological movies, and these materials could make up the emotional inexperience weaknesses of students precisely when learning. Therefore, psychological movies make the abstract psychological theory manifest specifically, emotionally and physically, and thus become a visual and specific carrier for students when learning psychological theory.

For example, in the teaching of "Personality Psychology", contents such as what is personality, what are personality features, what is personality trait theory and so on, were tough for students to understand. During the appreciation of the movie "Concubine", through the well-informed history story of Chu-Han hegemony and analyzing the different attitudes and behaviors of characters such as Xiang Yu, Liu Bang, Lv Zhi in the film, students usually had a clear view of the personal performances and unique personalities of main characters, as well as primary personality traits and central traits of each character. In this way, the original abstract and ambiguous content in the minds of the students would gradually become lively, and students would have a more profound understanding of the corresponding theory.

\subsection{Provide realistic situations similar to reality for students to acquire knowledge and skills}

Constructivism showed that best way for learners to complete the meaning construction of what they have leaned was to let learners feel real and experience in the real-world environment, not just to listen to teachers the introduction and explanation about such experience. Therefore, teaching should make learning implement in the situation similar to the reality with attempts to solving the problems encountering in their real lives (Mo, 2002, P. 134).

In the learning of psychological counseling and treatment, due to the lack of practical experience, students' grasp of certain theory and technology was limited to simple understanding and superficial cognition. They had unclear view of the symptoms of several psychological problems, and did not find the real value of some counseling and treatment methods and technology, let alone correct and effective application. In psychological movies, there are many subjects on psychological counseling and treatment. For example, "Horse Whisperer", the film hero Tom Booker gave a long psychotherapy to the disabled girl, Grace, who hit a car accident, in order to cure her psychological obstacles. He adopted many treatments, such as natural tension, motivation, catharsis and so on. At the same time, the treatment principle of active unconstraint, respect and empathy, as well as the treatment style of humanism embodied vividly. Such films showed many psychological counseling and treatment situations near to the reality through the portrayal of psychological counseling and treatment process in a certain case. Through the film appreciation, students would make sure how to identify symptoms of psychological problems in a real scenario, how to seize keys to psychological problems, how to share empathy exchanges with visitors, and how to implement the principles and methods of psychological counseling and treatment. Therefore, the appreciation of such films is of significant help for students to understand psychological counseling and therapy theories and enhance the operation level.

\subsection{Improve students' mastering level of knowledge}

In the teaching of certain knowledge related to psychology, I did a number of comparative experiments between two parallel classes. One class as the control, only routine teaching was implemented. Other class, as experimental class, when learning the contents about personality theory and psychological counseling, teachers 
and students appreciated movies and then discussed together. First, students of two classes were pre-tested on the relevant knowledge of the same content, and results showed that there was no significant difference of grades in general between two classes. After routine teaching in control and selected film appreciation and classroom discussion in experimental class, students of two classes had a unified test. Through the statistical analysis of grades, I found that scores of teaching contents such as personality theory, psychological counseling, personality and so on in experimental class were significantly higher than the control, which indicated that teaching in virtue of movies was obviously effective for students to enhance their learning achievements.

\section{Thinking of the application of films in the practice of psychology teaching}

\subsection{The combination of students' "appreciation" and teachers' "analysis"}

If letting students appreciate psychological movies simply, their attention would be attracted by the bizarre suspense plots of the film, and the content and objectives they concerned always deviated from the original intention of teachers who let them appreciate the movies. Therefore, the appreciation of students should integrate with the analysis of teachers, in order to achieve the desired teaching effectiveness of teachers. In teaching practice, teachers could take out some plots related to courses and analyze and interpret them after students appreciated movies; they could bring forward some issues which need consider and concern, let students enjoy the movies with questions, in order to enhance the purpose of appreciation; they could explain and analyze simultaneously when students enjoyed the movies; they could edit films first, delete the story plots unrelated to the teaching content, or in order to keep the integrity of stories, tell students these plots using general language, and then appreciate and explain alternately. Taken together, in this process, effective exertion of teachers' leading role was the premise to promote the psychological movies to exert their values.

\subsection{Correct orientation of psychological movie's role in teaching}

Movie teaching was only complementary to classroom teaching, and one of assistant forms of classroom teaching. Although psychological movies were of considerable help to complete the teaching task of psychology-related courses and enhance teaching quality, their function should not be exaggerated unilaterally. Furthermore, psychological movies should not be abused in the teaching of psychology-related courses, or psychology classes would become a film appreciation class, and a recreation class. In that way, not only students were difficult to obtain systematic and complete knowledge, but also leading role of teachers in teaching would lose. Therefore, the application of psychological movies to carry out the teaching of psychology-related courses couldn't become the dominant form of psychology teaching. It should only combine with other forms of teaching, through mutual cooperation and complementarity and appropriate and timely employment, and then their active role in teaching would exert.

\subsection{Limitations in the teaching in virtue of psychological movies}

Firstly, teachers should consider a variety of requirements when selecting movies, which is a more time-consuming work. Film Arts have been born for hundreds of years, and hundreds of thousands of movies came out. Hundreds of movies have been produced and published annually in China. Selecting appropriate movies from vast film works for psychological teaching really need more time and energy. In order to use psychological movies in teaching, teachers should not only study film art and pay attention to film art development at home or abroad, but also take time to appreciate movies by themselves, only in this way, could they collect movies with psychology values. Meanwhile, teachers should consider time characteristics, psychological characteristics and hobbies that students possess in the selection of movies, try to select those works with strong characteristics of times, and also consider the amusement and artistry of the selected movies. It is more important to consider that classroom teaching is a particular process of educating people, and thus selecte movies should be prominent ideological works. Consequently, given these requirements, teachers should screen and select ideal ones from film works patiently.

Secondly, appreciation process is relatively time-consuming. Now movies could take 2 hours, or even 3 hours. The full appreciation of a film could occupy much time of lessons. Sometimes teachers should advise students to appreciate the same film for several times. Teachers should also explain and analyze the corresponding contents, or guide students to discuss. Hence, compared to the simple teaching pedagogy, completing specific teaching task through the appreciation of the psychological movies require a larger amount of hours.

Thirdly, the elaboration of psychological problems in some movies was quite superficial, and short of integrity. "Edward Doctor" is one of the most classic psychological movies. Many theories of psychoanalytic doctrine, such as subconsciousness, childhood experiences, dream interpretation, psychological analysis technology and so on, have been reflected in the movie, but these contents were only designed and arranged by the director 
according to the requirement of plots whose connections were loose among them. The film only gave a superficial description about these contents, lack of profound theoretical study. It was hard for people to see their status in the theories of psychoanalytic doctrine, and they were difficult to form a relatively complete system. After all, psychological movies were not specially tailored for psychology. Even the portrayals of psychological phenomena in some films were completely untrue, and taking the film "Heroic Duo" as an example, the hypnosis was described to be so incredible, or even an eye contact could make another people asleep quickly, which was totally inconsistent with the fact. Therefore, in the practice of teaching, teachers should carefully screen something right or wrong, proper and improper in the movies, in order to avoid something misleading to students.

In addition, movies which were more successful in the portrayal of psychological phenomena are mostly western films, especially for the American films. Social, family and personal values penetrated in some movies were inconsistent with our adored values, and even harmful to the health development of young people. Consequently, teachers should guide students to identify and animadvert on those contents with particular emphasis, and thus resist their adverse effects.

\section{References}

Jin, Y.P., Y, H. \& Yong, F. (1999). Appreciation of film and television art. Capital Normal University Press, 48-60.

Lv, X.F. (2005). Psychological issues in films. Science and China Youth Technology, (11):39-40.

Mo, L. (2002). Educational psychology. Guangdong Higher Education Press, 268-269, 134. 